\title{
Brains at necropsy: to fix or not to fix?
}

\author{
A Katelaris, J Kencian, J Duflou, J M N Hilton
}

\begin{abstract}
Aim-To investigate whether routine formalin fixation of all brains coming to necropsy increases the rate of detection of brain abnormalities relative to either selective formalin fixation of brain tissue or fresh dissection of all brain tissue at the time of post mortem examination.

Methods-A retrospective study of 300 medicolegal necropsies was performed. One hundred cases were examined by doctors with little or no formal training in necropsy pathology. One hundred cases were examined by forensic pathologists, who used their discretion as to whether to fix the brain in formalin. A further 100 cases were examined by neuropathologists; all the brains had already been fixed at the time of necropsy.

Results-When examined by doctors with little or no formal necropsy pathology training, only $15 \%$ of brains were found to be abnormal. In the case of selective fixation, $33 \%$ were found to be abnormal. When there was obligatory fixation of all brains, $51 \%$ of all brains were found to be abnormal.

Conclusions-It is concluded that formalin fixation of the whole brain at the time of necropsy, followed by detailed examination of the brain by a neuropathologist, significantly increases the detection rate of brain pathology at necropsy.
\end{abstract}

(F Clin Pathol 1994;47:718-720)

Neuropathologists generally believe that formalin fixation of the undissected brain removed from the body at the time of necropsy is preferable to dissection of the fresh, unfixed brain during necropsy. ${ }^{12}$ Although this is accepted belief we have been unable to find any previous publications in support of this practice.

Removal of tissue, including the brain, from the body at necropsy is considered by some to be a contentious issue, because it contravenes the social mores of many cultures, ${ }^{3}$ a factor made much of by the popular press. ${ }^{4}$ Formalin fixation of the brain generally takes at least three weeks to permit optimal examination of the tissue. This results in a substantial delay in the finalisation of a necropsy report. Adequate examination of brain tissue is also costly and time consuming. Furthermore, there is a worldwide shortage of trained neuropathologists.

\section{Methods}

A retrospective study of the necropsy reports of 300 cases was conducted. All necropsies were conducted as part of an investigation required by the New South Wales (NSW) Coroners' Act. This Act, when read in conjunction with the Registration of Births, Deaths and Marriages Act, requires the coroner to investigate sudden unexpected death, deaths occurring under suspicious circumstances, from overt or covert violence, and deaths in custody, etc. Similar legislation exists in all states and territories of Australia. In the Sydney metropolitan area and in the Hunter region of New South Wales the inquiry into all "coronial" deaths includes a comprehensive postmortem examination by specialist forensic pathologists or trainee pathologists under their supervision. Outside these areas, medicolegal necropsies are conducted by non-forensic pathologists, or more commonly, by non-specialist doctors known as government medical officers (GMOs). The GMOs may, but are currently not required, to refer material to the New South Wales Institute of Forensic Medicine for further examination, usually of a histological nature.

The material to which this study relates is divided into three groups:

Group $A-$ One hundred examinations conducted in rural areas of New South Wales by GMOs whose usual practice is to dissect brain tissue in the fresh state at the time of their initial examination. The necropsy reports and histological material (which did not necessarily include central nervous system samples) were available to us.

Group B-This group of 100 consecutive cases consisted of cases coming to necropsy at the New South Wales Institute of Forensic Medicine in 1988 by forensic pathologists or pathology trainees. At the Institute at that time brains were dissected fresh, unless an opinion was to be sought from a neuropathologist. This further opinion was usually sought in cases of complex trauma or known other intracranial pathology.

Group C-The third group of 100 consecutive cases consisted of cases coming to necropsy at the New South Wales Institute of Forensic Medicine in 1992 by forensic pathologists or pathology trainees. All these brains had been formalin fixed and were then examined by neuropathologists or forensic pathologists with an interest in neuropathology. From early 1991, all brains from bodies examined at the Institute were formalin fixed and examined in this way. 
Decomposed cases, in which formalin fixation of the whole brain was not indicated, were not included.

The findings were grouped into categories of normal, acute trauma to the brain, and other neuropathology. The "other neuropathology" group included, among others, cases of prolonged survival after head injury, brain tumours, degenerative brain disease and cerebrovascular disease resulting in neurological deficit. Cases of non-complicated atherosclerotic cerebrovascular disease were classified as normal for the purposes of this study.

The null hypothesis that there would be no difference between the three groups in their assignment of the various diagnostic categories was analysed using the $\chi^{2}$ test.

\section{Results}

Three hundred coronial necropsy reports were reviewed, 100 in each of the three groups. Table 1 shows the distribution of cases by manner of death in the three groups-there were no significant differences between the groups. The brain had been examined in all cases. Table 2 presents the frequency of neuropathological findings in the three groups.

In group A two brains had been fixed whole and subsequently examined by a neuropathologist. One showed a large superficial cerebral abscess with purulent meningitis, the other multiple old traumatic lesions. The macroscopic necropsy report described pathological lesions in a further 13 cases: there were eight gunshot wounds to the head, four cases of severe motor vehicle trauma and one case of old cerebral infarction.

Table 1 Manner of death

\begin{tabular}{|c|c|c|c|c|c|c|}
\hline & $\begin{array}{l}\text { Medical } \\
\text { illness }\end{array}$ & $\begin{array}{l}\text { Suicidel } \\
\text { drug } \\
\text { overdose }\end{array}$ & $\begin{array}{l}\text { Road } \\
\text { traffic } \\
\text { trauma }\end{array}$ & $\begin{array}{l}\text { Other } \\
\text { trauma }\end{array}$ & Homicide & Undetermined \\
\hline $\begin{array}{l}\text { Group } A \text { : } \\
\text { Necropsy by non-pathologist. } \\
\text { Tissue referred if considered } \\
\text { necessary. }\end{array}$ & 61 & 22 & 5 & 10 & 0 & 2 \\
\hline $\begin{array}{l}\text { Group } B \text { : } \\
\text { Necropsy performed by forensic } \\
\text { pathologist. Selected brains } \\
\text { fixed and examined by } \\
\text { neuropathologist. }\end{array}$ & 64 & 9 & 10 & 17 & 0 & 0 \\
\hline $\begin{array}{l}\text { Group } C \text { : } \\
\text { Necropsy performed by } \\
\text { forensic pathologist. All brains } \\
\text { formalin fixed and examined by } \\
\text { neuropathologist. }\end{array}$ & 59 & 18 & 6 & 15 & 1 & 1 \\
\hline
\end{tabular}

Table 2 Brain dissection findings

\begin{tabular}{lllllllll}
\hline & \multicolumn{3}{l}{ Group $A$} & & \multicolumn{2}{l}{ Group B } & \\
\cline { 2 - 3 } & Unfixed & Fixed & Total & & Unfixed & Fixed & Total & Group C \\
\hline Normal & 85 & 0 & 85 & 52 & 15 & 67 & 49 \\
Acute trauma & 12 & 0 & 12 & 10 & 10 & 20 & 16 \\
Other neuropathology & 1 & 2 & 3 & 8 & 5 & 13 & 35 \\
Total & 98 & 2 & 100 & 70 & 30 & 100 & 100 \\
\hline
\end{tabular}

Group A: necropsy performed by non-pathologist. Tissue referred if considered necessary. Group B: necropsy performed by forensic pathologist. Selected brains fixed and examined by neuropathologist.

Group C: necropsy performed by forensic pathologist. All brains fixed in formalin and examined by neuropathologist.
In group B $30 \%$ of brains were fixed before being examined by a neuropathologist. Of these, $50 \%$ had major pathology. In contrast, only $26 \%$ of the brains examined in the unfixed state showed extensive pathological lesions.

In group $\mathrm{C}$ where all brains had been fixed before examination, $51 \%$ showed extensive pathology. This was a higher rate of detection of pathology than if the brain had been examined either by a GMO or using the protocol for group $B$.

When comparing the various groups, the difference was highly significant $\left(\chi^{2}=43.201\right.$; $\mathrm{df}=4 ; \mathrm{p}<0.001)$. This is mainly due to the difference in group $A$ and group $C$ in their categorisation of "other neuropathology". There was no significant difference in the detection of acute trauma pathology between the various groups.

The data were further examined using $2 \times 2$ $\chi^{2}$ analyses, comparing differences in assignment to diagnostic categories in the various groups. There were significant differences in the diagnoses between groups $\mathrm{A}$ and $\mathrm{B}\left(\chi^{2}=\right.$ $10.38 ; \mathrm{df}=2 ; \mathrm{p}<0.006)$, groups $A$ and $C$ $\left(\chi^{2}=37 \cdot 19 ; \mathrm{df}=2 ; \mathrm{p}<0.0001\right)$, and groups $B$ and $C\left(\chi^{2}=13.32 ; \mathrm{df}=2 ; \mathrm{p}<0.001\right)$.

\section{Discussion}

Fixation of whole brains removed at necropsy may be an emotive issue. Reliable current technology entails a delay in completion of the examination of at least three weeks. We have had little success with more rapid fixation techniques, including microwave fixation of the brain. Next of kin may not want to bury or cremate an incomplete body, ${ }^{4}$ although rational explanation of the nature of a postmortem examination can allay these concerns. Routine fixation and thorough examination of all such brains adds considerably to the cost of necropsy, and can cause major difficulties with storage and later disposal of the tissues. Suitably qualified neuropathologists need to be available, at least on a part-time basis. They are a scarce resource and add further to the real but often hidden cost of a meaningful postmortem examination.

The major advantages associated with this method of examination include the ability to perform a more precise and useful topographic study of the brain, and detection of small but important lesions. ${ }^{2}$ Appropriate blocks for histological examination can be more readily selected, without which the definitive diagnosis of such conditions as multiple sclerosis, Huntington's chorea, the differential diagnosis of the later onset dementias, diffuse axonal injury, ${ }^{5}$ etc, may not be made.

The purpose of a postmortem examination is to describe and delineate pathological processes in the human body. The medicolegal necropsy is also directed to establishing the cause of death for the coroner. In this particular study detailed examination of the brain did not materially influence the establishment of the cause of death beyond the examination 
of other organ systems. However, pathology in addition to the crude cause of death was described in $28 \%$ of the cases where the brain was adequately examined after fixation. So although proper examination of the brain is time consuming and more expensive, neglecting so to do would be a dereliction of duty for what is in essence the pathologist's patient.

Our study shows that formalin fixation of the whole brain before examination results in a significantly increased detection rate of antemortem pathology. Examination of unfixed material by a doctor who has not had formal postgraduate training in pathology results in a low detection rate of both traumatic and nontraumatic central nervous system pathology. GMOs detected no small or diffuse traumatic lesions, but they did detect a problem in three cases, subsequently confirmed by a neuropathologist. More subtle non-traumatic pathology was not described by GMOs.

Fixation of preselected brains results in a higher detection rate of important pathology as illustrated in group B. By comparing the results of groups A and B with those of group $C$, we have shown the advantages of formalin fixation of brains before examination and how the optimal result is obtained when such material is examined by a neuropathologist.

We conclude that the advantages of examination of the brain after fixation outweigh the disadvantages of delaying the finalisation of the necropsy report. At necropsy all brains should be fixed before detailed examination if the maximum accurate diagnostic information is to be obtained.

1 Esiri MM, Oppenheimer DR. Introduction: General methodology and pathological cellular reaction. In: Diagnostic neuropathology. Oxford: Blackwell Scientific Publications, 1989:2.

2 Okazaki H. Introduction. In: Fundamentals of neuropathology. New York: Igaku-Shoin, 1983:2.

3 Hill RB, Anderson RE. Decline of the autopsy: reasons in society. In: The autopsy-Medical practice and public society. In: The autopsy-Medical pracei
policy. Boston: Butterworths, 1988:165.

4 Ongaro $D$. The last rights: Mum in rage over son's brain autopsy. The Daily Telegraph Mirror. Sydney, 21 April 1992:28.

5 Simpson RH, Berson SD. The postmortem diagnosis of diffuse cerebral injuries, with special reference to the importance of brain fixation. $S$ Afr Med $\mathcal{f} 1987 ; 71: 10-4$. 